ARTÍCULOS

\title{
Análisis de la reseña al texto "Políticas Educacionales del Gobierno de Chile", realizada por el profesor Juan Iglesias Díaz (1976)
}

\author{
Analysis of the review of "Educational Policies of the Government of Chile" \\ by Professor Juan Iglesias Diaz (1976)
}

\author{
Dr. Marcelo Arancibia Herrera \\ Instituto de Ciencias de la Educación \\ Facultad de Filosofía y Humanidades \\ Universidad Austral de Chile \\ marceloarancibia@uach.cl
}

Telf.: (56) 63221262

\section{RESUMEN}

El presente ensayo es una análisis crítico a la reseña escrita por el profesor Juan Iglesias Díaz, publicada en el primer número editado de la revista Estudios Pedagógicos, cuyo título es "Políticas Educacionales del Gobierno de Chile".

Palabras clave: reseña, educación, gobierno

\section{ABSTRACT}

This paper is a critical analysis of the review written by Professor Juan Iglesias Diaz, published in the first issue of the journal Estudios Pedagógicos entitled "Educational Policies of the Government of Chile".

Key words: review, education, government 
Estudios Pedagógicos, Número Especial 40 años: 151-155, 2016

ANÁLISIS DE LA RESEÑA AL TEXTO “POLÍTICAS EDUCACIONALES DEL GOBIERNO DE CHILE”, REALIZADA

POR EL PROFESOR JUAN IGLESIAS DÍAZ (1976)

\section{INTRODUCCIÓN}

El breve texto presenta un análisis de un folleto homónimo al título del artículo, el cual es elaborado por el Ministerio de Educación de la época y que contiene "principios, políticas y orientaciones educacionales en que se basarán las estrategias para el funcionamiento del Sistema Nacional de Educación” (Iglesias Díaz, 1976: 99). De esta cita, y de su contextualización al año 1976, se desprende que este folleto inicia un proceso de renovación de la educación en Chile, con posterioridad al golpe militar del año 1973, pues se definen "principios", es decir cuestiones ideológicas; "políticas", o sea directrices para la acción de los organismos públicos; y, por último, "orientaciones" es decir conductos o formas de ejecutar las acciones. Con todo, el texto manifiesta que aún están pendientes las definiciones de estrategias para la ejecución.

La reseña manifiesta explícitamente que el texto es una "exposición sumaria" de los elementos fundamentales de una doctrina educacional. Todo ello refuerza nuestra visión de constituirse en un texto ideológico, más un tanto contradictorio con un régimen que se declaraba des-ideologizado. Es un hecho también para el autor que este folleto propicia como objetivo "más preciado" (sic) la Unidad Nacional, lo cual no cabe duda es propio de una doctrina (ideología) militar.

En principio, aún cuando no lo declara el autor, podemos advertir en el documento un fuerte sesgo ideológico y la intención de trasformación del sistema educacional hacia la formación de conductas ciudadanas con un fuerte componente nacionalista. Con ello, no es erróneo pensar que este folleto analizado da pie a los futuros cambios radicales del sistema escolar chileno en la década del 80 que provocan la mercantilización del sistema escolar (Falabella, 2015).

Más adelante, el Prof. Iglesias analiza elementos técnicos del documento, los cuales siento son bastante contingentes con nuestra realidad actual, a 40 años de lo por él descrito. Pasemos a analizar cada uno de estos aspectos.

\section{RENOVACIÓN CONTINUA V/S REFORMAS EDUCACIONALES}

No cabe duda que el concepto de "renovación continua", valorado positivamente por el autor, se entiende aquí como la superación de la lógica ministerial de las "reformas educacionales". Ellas se efectúan con bastante periodicidad y secuencia en Chile, a partir de la década del 60, con el sello de cada uno de los gobiernos de turno. Aparentemente este concepto, para el autor, viene a cambiar el sentido de "partir desde cero" con cada reforma, pues la concepción de Renovación Continua a mi parecer connota un modo de entender el fenómeno educativo en cambio permanente.

En la actualidad hemos vivenciado (porque no decirlo, sufrido) la constante aparición de "reformas" que finalmente no terminan cambiando mucho, o bien son cambios de algunos aspectos del sistema escolar. En tal sentido, ellas están más en la lógica de la Renovación Continua, de un sistema que sin duda necesita de mejoras sustantivas.

\section{EXPERIMENTACIÓN EDUCACIONAL SISTEMÁTICA}

En Chile esta idea de experimentación educacional emerge, como política en el sistema, con la creación del Centro de Perfeccionamiento, Experimentación e Investigaciones 
Pedagógicas en la década de los 60 (CPEIP), cuya misión fue dotar a la formación de profesores de un nivel mínimo de base científica. Sin embargo, es preocupante la alusión del profesor Iglesias en cuanto a valorar el hecho de que este rango de cientificidad sea otorgado al CPEIP, quedando las Universidades solo preocupadas del perfeccionamiento, separando así a las escuelas y facultades pedagógicas de su función primordial: la investigación. Podemos vislumbrar en este folleto, en consecuencia, el germen de la caída al precipicio de las carreras de educación de nuestro país, en cuanto solo fue preocupación del cuerpo académico la docencia y no la investigación o vinculación con el medio.

\section{EDUCACIÓN PERMANENTE}

Este concepto de educación se reduce, según el autor, a la educación de adultos y durante la vida productiva, asociándolo desde mi perspectiva con la eficiencia para el mundo del trabajo, dejando de lado, concepciones contemporáneas de la formación humana y de la persona como ser integral. Este concepto, así planteado, muestra también la semilla de la posterior visión economicista de la educación que tendrá la dictadura militar, iniciada la década de los 80 .

\section{SUBSIDIARIDAD}

Ha sido relevante en la revisión de este documento darnos cuenta como, ya en el año 1976, desde el Ministerio de Educación surge la idea de darle cabida a las iniciativas privadas en la educación escolar en Chile, instalando el carácter de rol subsidiario al Estado, fenómeno que luego se verá concretado con la municipalización del año 1982 (Donoso y Donoso, 2009), con el consecuente pago por asistencia de los alumnos matriculados en una institución.

Asimismo, el autor valora positivamente este concepto en cuanto fomenta la participación de iniciativas privadas en el mejoramiento de la Educación Nacional, lo cual muestra que estas ideas no estaban muy alejadas del sentir de la academia en esos años, por cierto considerando el contexto de represión hacia las ideas y el libre pensamiento que existía entonces en Chile.

\section{INDIVIDUALIZACIÓN DE LA ENSEÑANZA}

Este concepto se asocia a la necesidad de universalidad de la enseñanza primaria que permita aumentar la cobertura, disminuyendo la deserción y el fracaso. Este punto es interesante, pues nos remonta a la idea que atendiendo las individualidades podemos disminuir las brechas de fracaso, es decir una enseñanza masiva o centrada en el grupo (promedio o estándar) no ha permitido que los estudiantes desfavorecidos permanezcan en el sistema escolar. Con todo, una de las causas del fracaso escolar tiene que ver con la poca atención al individuo.

No cabe duda que este fenómeno aún está vigente, aun cuando la cobertura del sistema escolar primario en Chile alcanza guarismos históricos de mantención (superiores al 90\%). Sin embargo, sigue aún la reflexión crítica respecto de los procesos de individualización, 
Estudios Pedagógicos, Número Especial 40 años: 151-155, 2016

ANÁLISIS DE LA RESEÑA AL TEXTO “POLÍTICAS EDUCACIONALES DEL GOBIERNO DE CHILE", REALIZADA

POR EL PROFESOR JUAN IGLESIAS DÍAZ (1976)

en tanto se pierde lo colectivo o social del proceso de aprendizaje. Ante ello es conveniente hablar de proceso de desarrollo de la persona en base a una educación situada (contextualizada).

\section{PREPARACIÓN VOCACIONAL ESPECÍFICA}

A partir de este documento, se orienta a la educación básica con un enfoque formativo vocacional específico; esto quiere decir que ya en el ciclo primario se debe ir formando la vocación laboral de los niños y niñas, lo que vuelve a definir un marcado sesgo economicista de esta política educativa dirigida a responder a las demandas del mundo del trabajo.

\section{NIVELES DE CARÁCTER TERMINAL}

En este aspecto se refuerza lo anteriormente planteado, pues cada ciclo formativo debería considerarse como un nivel en sí mismo, una etapa formativa que pueda ser reconocida como tal. Dicho carácter (de cada nivel formativo) se justifica en el contexto de lo que entendemos como una política de formación permanente.

\section{EXTENSIÓN EDUCACIÓN PARVULARIA Y DIFERENCIAL}

También llama la atención que en este documento reseñado se hable de la ampliación de cobertura, tanto de la educación preescolar como de la especial. En el caso de la educación inicial, se valora la preocupación por extender su cobertura, dando más posibilidades a niños de escasos recursos; de este modo, se dice, se mejorarán "los rendimientos escolares y vocacionales".

En cuanto a la educación diferencial, se hace alusión al conflicto que pueda generarse en torno a la discusión sobre si incluirla en los centros escolares comunes o en escuelas separadas (especiales). Se trata de una discusión que aún persiste en algunos espacios educativos actuales frente a la ley de inclusión y los Programas de Integración Educativa (PIE), que considera la ley para los colegios comunes que integren estudiantes con necesidades educativas especiales.

\section{MAPA ESCOLAR}

Por último, el folleto analizado por el autor habla de la necesaria investigación que permita generar un mapa de la realidad nacional, que apoye los procesos de regionalización, que aparentemente se inician en este período, y que, después, se verán traducidos en la municipalización del sistema escolar chileno.

Finalmente, el autor advierte que es necesario, para tener una visión más extensa y trascendental del documento, esperar tener a la vista la planificación de estrategias educativas asociadas a esta política. Sin embargo, termina augurando valiosas las modificaciones. 


\section{CONCLUSIONES}

Realizar el análisis de esta reseña a una política educativa de hace cuatro décadas, me ha permitido conocer parte de las iniciativas e ideología pedagógica de los primeros años de la dictadura militar, que en parte nos permite identificar el germen de su posterior reforma pedagógica y administrativa de privatización del sistema escolar, transformándolo en un mercado.

En segundo término, la reseña refleja cuestiones que siguen siendo aún una preocupación por resolver respecto a las políticas educativas y la gestión de un sistema que no ha podido dar respuesta a necesidades siempre presentes en la escuela, el profesorado y la realidad educativa. Ello no es un simple consuelo; más bien lo planteo como una exigencia y un desafío para acabar con un sistema educativo que por más de cuarenta años ha generado desigualdad, segregación y bajos logros de aprendizaje en nuestros estudiantes (Donoso et al., 2012).

Desconocemos si este documento es el germen de lo que ocurre luego con nuestro sistema escolar en la década de los ochenta. Sin embargo, nos ha permitido descubrir principios, políticas y orientaciones que, muchas de ellas, se encuentran en la base de las transformaciones, tanto constitucionales (libertad de enseñanza) como organizativas (administración municipal) y económicas (subvención por alumno), que se reflejan de modo concreto en la década de los ochenta y se solidifican en la Ley Orgánica Constitucional de Educación del 10 de marzo de 1990 (LOCE), un día antes de que finalizara la dictadura y que, con su substituta (LGE de 2009), muchos de estos principios se mantienen hasta nuestros días.

\section{REFERENCIAS BIBLIOGRÁFICAS}

Donoso, S. y Donoso, G. (2009). Políticas de gestión de la educación pública escolar en Chile (1990 -2010): una evaluación inicial. Ensaio: aval. pol. públ. Educ., vol. 17 (64), 421-448.

Donoso, S., Benavides, N., Cancino, V., Castro, M. y López, L. (2012). Análisis crítico de las políticas de formación de directivos escolares en Chile: 1980-2010. Revista Brasileira de Educação, vol. 17 (49), 133-158.

Falabella, A. (2015). El mercado escolar en Chile y el surgimiento de la Nueva Gestión Pública: El tejido de la política entre la dictadura neoliberal y los gobiernos de la centroizquierda (1979 a 2009). Educação \& Sociedade, vol. 36 (132), 1-21. 
